\title{
Originals
}

\section{Impaired autoregulation of blood flow in subcutaneous tissue of long-term Type 1 (insulin-dependent) diabetic patients with microangiopathy: an index of arteriolar dysfunction}

\author{
J. Kastrup ${ }^{1,2}$, T. Nørgaard ${ }^{3}$, H.-H.Parving ${ }^{2}$, O. Henriksen ${ }^{1}$ and N.A. Lassen ${ }^{1}$

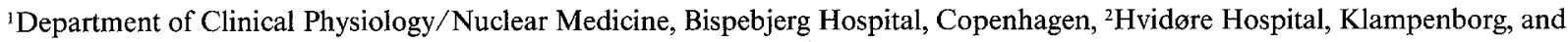 \\ ${ }^{3}$ Department of Pathology, Finsen Institute, Copenhagen, Denmark
}

\begin{abstract}
Summary. Autoregulation of blood flow in subcutaneous tissue was studied at the level of the lateral malleolus in eight long-term Type 1 (insulin-dependent) diabetic patients with clinical microangiopathy, eight short-term Type 1 diabetic patients without clinical microangiopathy and seven healthy control subjects. Blood flow was measured by the local ${ }^{133}$ Xenon washout technique. Mean arterial blood pressure was reduced by a maximum of $23 \mathrm{mmHg}$ by elevating the limb above heart level and elevating to a maximum of $70 \mathrm{mmHg}$ by head-up tilt; in the latter position venous pressure was kept constant and low by activation of the leg muscle vein pump (heel raising). Mean arterial blood pressure was thus varied between 60 and $160 \mathrm{mmHg}$. In normal and short-term diabetic subjects blood flow remained within $10 \%$ of control values during the changes in arterial blood pressure. In six of the eight Type 1 diabetic patients with clinical microangiopathy, autoregulation of blood flow was impaired, blood flow changing ap-
\end{abstract}

proximately $20 \%$ per $10 \mathrm{mmHg}$ change in arterial blood pressure; the slope of the autoregulation curves was significantly higher compared with the two control groups $(p<0.02)$. Resting mean arterial blood pressure was significantly elevated in long-term diabetic patients (median: $107 \mathrm{mmHg}$ ) compared with short-term diabetic (median: $85 \mathrm{mmHg}$ ) and control subjects (median: $91 \mathrm{mmHg}$ ) $(p<0.01$ and $p<0.02$, respectively). No correlation was, however, demonstrated between resting mean arterial blood pressure and the degree of disturbed autoregulation, but a relationship was demonstrated between the degree of disturbed autoregulation and the amount of periodic acid Schiff positive material in the terminal arteriolar walls of the investigated area $(p<0.05)$.

Key words: Autoregulation, diabetic microangiopathy, subcutaneous blood flow, Type 1 diabetes.
Autoregulation of blood flow is defined as the maintenance of almost constant blood flow during elective changes in arterial blood pressure, with venous pressure kept essentially constant [1]. This regulation has been demonstrated in many tissues and organs in animals and man [2-7].

The mechanisms underlying the autoregulatory response are still unknown. Neurogenic factors seem to be of no importance, since autoregulation is still present following chronic sympathetic denervation [2]. Changes in myogenic activity of the arteriolar smooth muscle cells due to structural changes [8-10] and/or local metabolic factors $[11,12]$ in response to alterations in perfusion pressure have been suggested as the most likely mechanisms.

During reduction in arterial blood pressure, autoregulation of blood flow in skeletal muscle and subcutaneous tissue [13] and of glomerular filtration rate [14] has been found to be impaired in Type 1 diabetic patients with clinical microangiopathy (nephropathy and retinopathy). Impaired autoregulation of cerebral blood flow has also been found in long-term diabetic patients [15]. Using an ingenious method, Sinclair et al. showed that autoregulation of retinal blood flow was progressively impaired in relation to the severity of the diabetic retinopathy [16]. All these studies suggest that diabetic microangiopathy might be responsible for the disturbance of the normal autoregulatory response. The aim of the present study was to investigate the influence of histologically proven hyalinosis of the terminal arteriole in the subcutaneous vascular bed on the autoregulatory response in the same tissue.

\section{Subjects and methods}

\section{Subjects}

The autoregulation of subcutaneous blood flow was investigated in three groups of volunteers. All subjects gave their informed consent and the investigation was approved by the local Ethical Committee. 
Table 1. Clinical data of Type 1 diabetic patients with and without clinical diabetic nephropathy and retinopathy and in non-diabetic control subjects

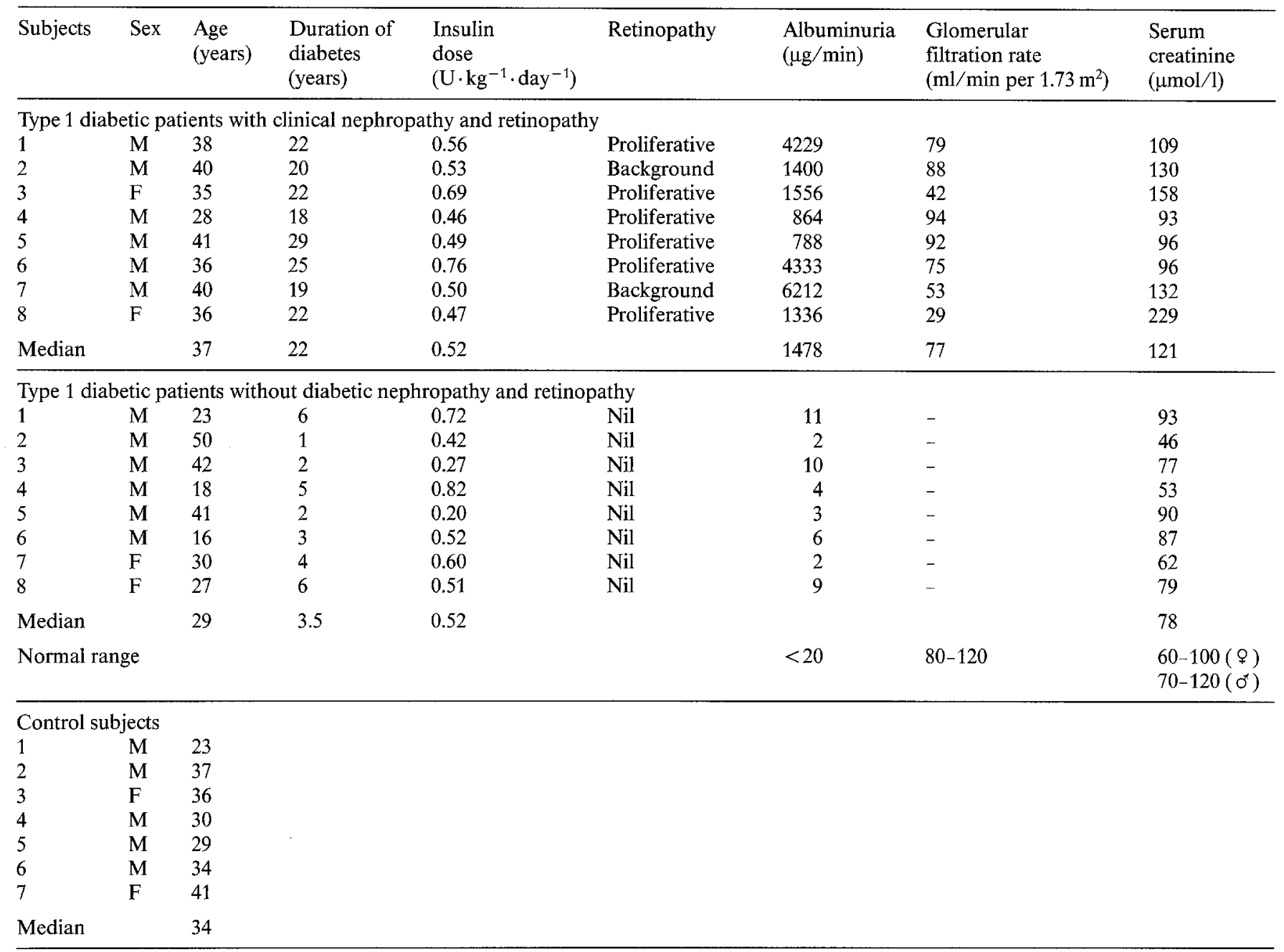

Group 1. Eight long-term Type 1 diabetic patients with clinical diabetic nephropathy and retinopathy (median age: 37 years, range; 28-41 years, two women and six men, Table 1). They were insulin-dependent from the time of diagnosis and received two daily injections of highly purified porcine insulin (Insulatard and Velosulin, Nordisk, Gentofte, Denmark, median dose: $\left.0.52 \mathrm{U} \cdot \mathrm{kg}^{-1} \cdot \mathrm{day}^{-1}\right)$.

Group 2. Eight short-term Type 1 diabetic patients without clinical diabetic nephropathy and retinopathy (Table 1). The patients were age- and sex-matched with group 1 (median age: 29 years, range: 18-50 years, two women and six men). Insulin dependency type and dosage were as for Group 1.

Group 3. Seven healthy control subjects (median age: 34 years, range: 23-41 years, two women and five men). They were characterized by normal fasting blood glucose, peripheral pulses and reflexes (Table 1 and 2). Both the diabetic patients and the control subjects had body weights within $10 \%$ of ideal body weight. Body weights were similar in Type 1 diabetic patients with (median $66 \mathrm{~kg}$, range $60-90 \mathrm{~kg}$ ) and without clinical microangiopathy $(73 \mathrm{~kg}, 60-78 \mathrm{~kg}$ ) and healthy subjects $(70 \mathrm{~kg}, 60-85 \mathrm{~kg})$.

The diabetic patients did not receive drugs except insulin. They were investigated after an overnight fast and were fasting during the investigation; the morning insulin dose was reduced to approximately $50 \%$ of normal dose.
Subcutaneous blood flow was measured $10 \mathrm{~cm}$ proximal to the lateral malleolus by the local ${ }^{133} \mathrm{Xenon}(\mathrm{Xe})$ washout technique [17], using ${ }^{133} \mathrm{Xe}$ dissolved in isotonic saline $(0.1-0.2 \mathrm{ml}, 1.0 \mathrm{mCi} / \mathrm{ml}$ ) (Amersham International, Amersham, Bucks, UK) [13, 18]. The fractional washout constant, $\mathrm{k}\left(\mathrm{min}^{-1}\right)$, was calculated by the least squares method from the regression line of the logarithmically transformed counting rates, corrected for background activity. Adipose tissue blood flow, $\mathbf{f}$, can be calculated from the following equation $\mathrm{f}=\mathrm{k} \cdot \lambda \cdot 100(\mathrm{ml}$. $100 \mathrm{~g}^{-1} \cdot \min ^{-1}$ ), where $\lambda$ is the tissue to blood partition coefficient [19].

\section{Protocol}

The investigations consisted of triads of flow measurements on the subcutaneous isotope depot. Each measurement lasted $8-15 \mathrm{~min}$, with the labelled area kept at one of the following positions; (1) reference level (ref. 1), midaxillary line; (2) elevated above or lowered below reference level (test); (3) returned to reference level (ref. 2). The time between changing position and starting the next set of measurements was about 5 min.

Relative blood flow was calculated as

$\frac{\mathbf{f}_{\text {rest }}}{\left(\mathbf{f}_{\text {ref. }}+\mathbf{f}_{\text {ref. } 2}\right) / 2}=\frac{\mathbf{k}_{\text {test }}}{\left(\mathbf{k}_{\text {ref. } .1}+\mathrm{k}_{\text {ref. } .2}\right) / 2}$

assuming a constant $\lambda$ during the measurements [20]. Room temperature was $23^{\circ} \mathrm{C}$ and remained constant. 
Table 2. Clinical findings in Type 1 diabetic patients with and without clinical diabetic nephropathy and retinopathy and in non-diabetic control subjects

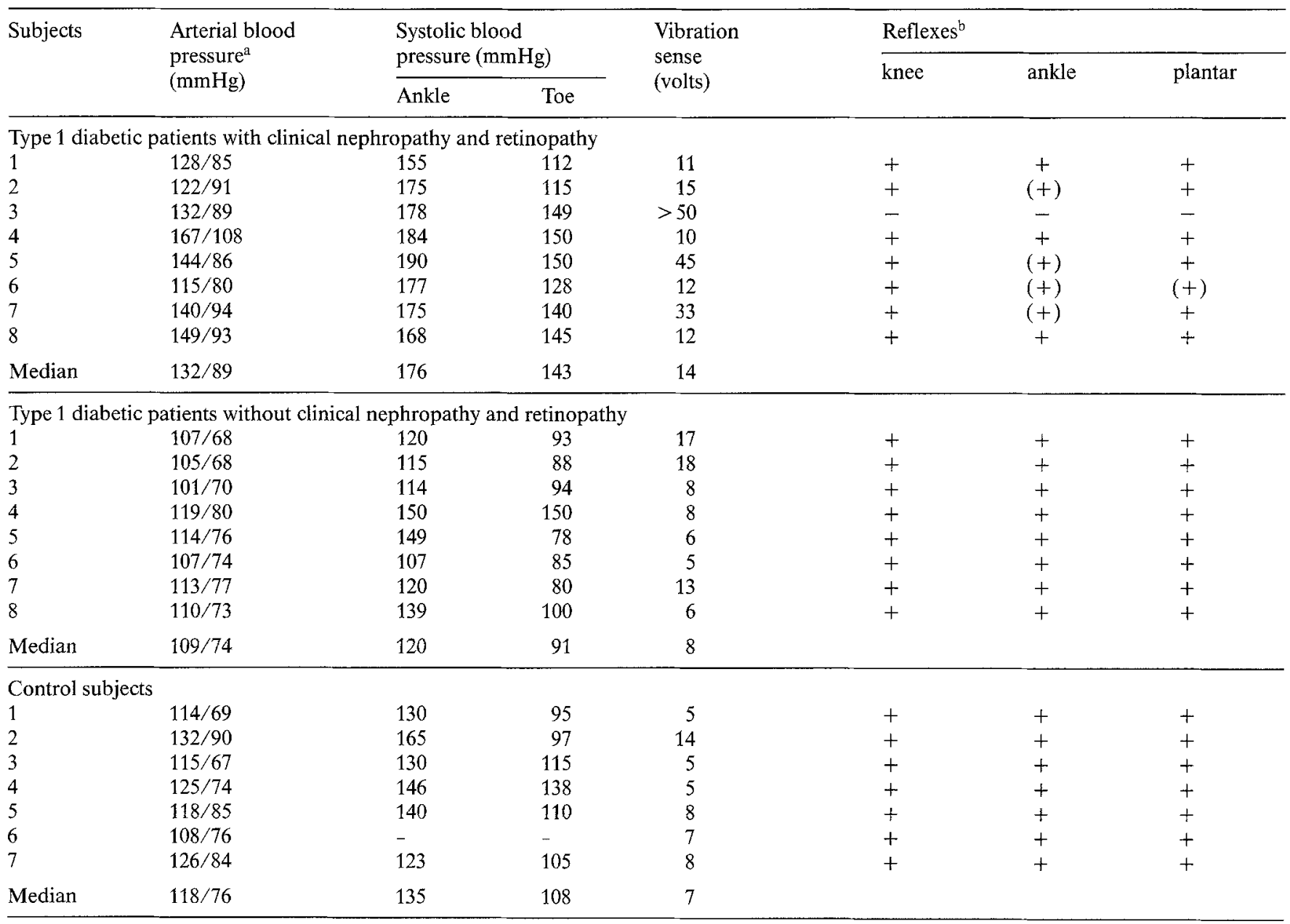

${ }^{a}$ Mean value of 8 to 12 measurements of the blood pressure after $15 \mathrm{~min}$ rest in supine position.

$b+=$ normal,$(+)=$ decreased, $-=$ absent

A cannula was inserted into a superficial vein on the dorsum of the foot and the venous pressure was measured directly using an infusion set as a venometer. Arterial blood pressure was measured on the upper arm with a standard clinical sphygmomanometer at heart level; diastolic pressure was recorded at Korotkoff phase 4. Mean arterial blood pressure (MAP) was calculated as the diastolic pressure plus one third of the pulse pressure. The arterial blood pressure in the investigated area was reduced by elevation of the limb 15 and $30 \mathrm{~cm}$ above heart level. When the limb was elevated care was taken to avoid pressure over the popliteal vein. The increases in arterial blood pressure were produced by tilting (head-up). The venous pressure was kept constant and low by activating the leg muscle vein pump by heelraising [21]. In this test situation the MAP was calculated as the MAP measured on the upper arm plus the hydrostatic pressure of the blood column from the investigated area to the heart level.

The slope of the autoregulation curves was calculated by the least squares method from corresponding values of relative blood flow and MAP without excluding any points.

Peripheral neuropathy was evaluated clinically and by measuring the vibration sense threshold level at the great toe and at the investigated area by biothesiometry [22]. To eliminate any influence from changes in neurogenic vasoconstrictor activity during the investigation, $0.1 \%$ lidocaine hydrochloride, $0.4-0.6 \mathrm{ml}\left(3.5 \cdot 10^{-4} \mathrm{~mol} / 1\right)$ [23] was injected together with the ${ }^{133} \mathrm{Xe}$. To ensure that total nerve paralysis was obtained during the measurements, the activity of the sympathetic vasoconstrictor nerve fibres was tested at the end of each inves- tigation of autoregulation by measuring the disappearance rate of injected ${ }^{133} \mathrm{Xe}$ in (1) reference level; (2) head-up tilt $\left(60^{\circ}\right) ;(3)$ reference level [24]. During head-up tilt $\left(60^{\circ}\right)$ and with normal peripheral sympathetic nervous activity, the blood flow is reduced to approximately $50 \%$ of the blood flow in horizontal position. In a subsequent examination, performed on a separate day, the same triple measurements were performed without lidocaine in order to determine the degree of diabetic sympathetic neuropathy.

After the investigation biopsies ( $2 \mathrm{~mm}$ in diameter) were obtained, sections were stained with haematoxylin and eosin and periodic acid schiff (PAS). The thickness of the terminal arteriolar basement membranes were graded semiquantitatively from $1+$ to $4+$ using light microscopy [25]. The examinations were performed randomly and "blindly" by one investigator (TN).

Ankle and toe systolic blood pressures were measured by the strain-gauge technique [26]. Urinary albumin concentration was measured using the radial immunodiffusion technique [27]. Glomerular filtration rate (GFR) was measured after a single intravenous injection of ${ }^{51} \mathrm{Cr}$-EDTA [28]. Blood glucose was measured every hour using a glucose oxidase method on an Autoanalyzer II (Technicon, Tarrytown, New York, USA).

\section{Statistical methods}

Wilcoxon's test for unpaired data and Fisher's exact test for fourfold tables were used to test for differences between the groups. 

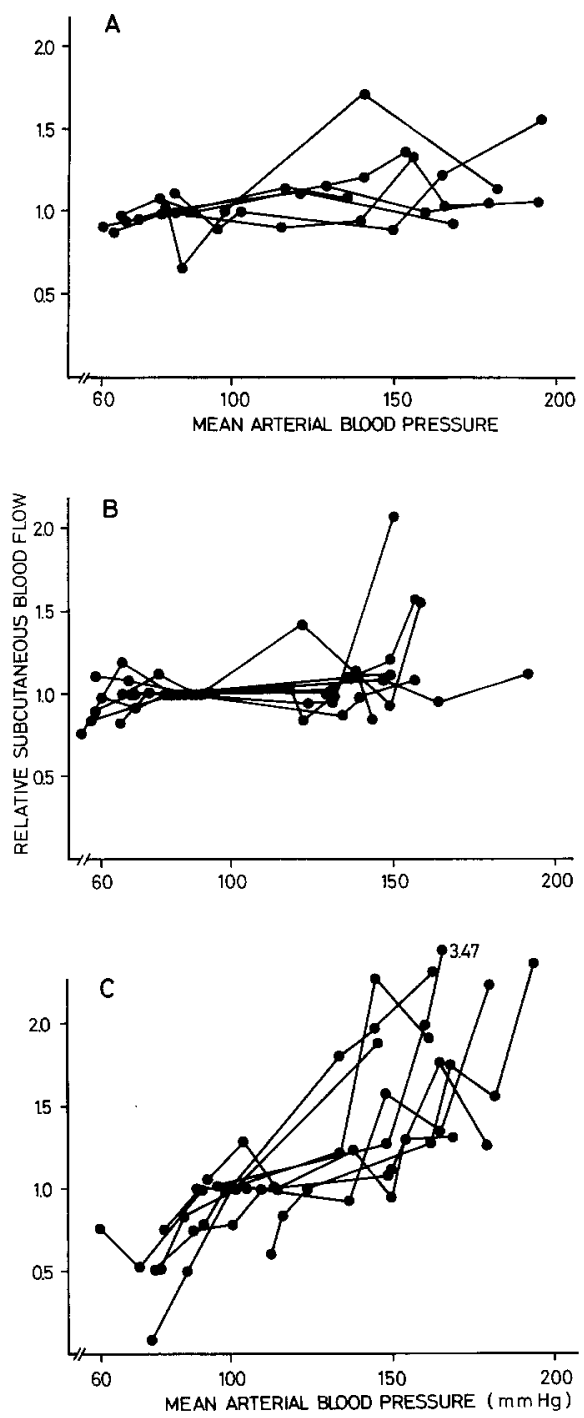

Fig. 1A, B and C. The autoregulation curves of the subcutaneous blood flow in seven healthy controls (A), eight Type 1 diabetic patients without clinical nephropathy and retinopathy (B) and eight Type 1 diabetic patients with clinical nephropathy and retinopathy (C). Relative subcutaneous blood flow is the blood flow during changed blood pressure divided with the mean value of the blood flow in horizontal position before and after the change in blood pressure. Mean arterial blood pressure is the calculated blood pressure in the investigated area

\section{Results}

\section{Autoregulation}

Both the healthy subjects and the short-term Type 1 diabetic patients without clinical nephropathy and retinopathy had almost unchanged subcutaneous blood flow during changes in arterial blood pressure between $70-150 \mathrm{mmHg}$ (Fig. 1). Since the venous pressure was kept constant and low, the findings imply normal autoregulation of blood flow in this pressure range.

However, an increase in blood flow was seen in three out of the six short-term diabetic patients in whom the mean arterial blood pressure was elevated to

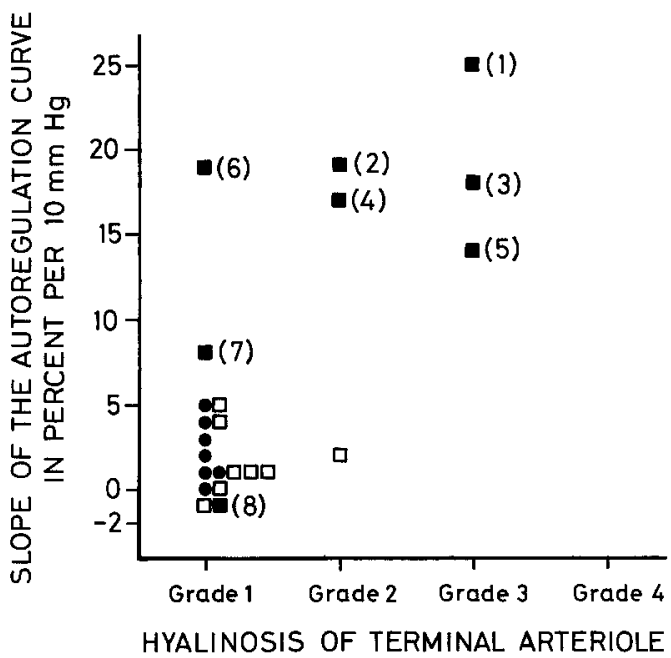

Fig. 2. Relationships between the diabetic microangiopathy in the terminal arterioles (arteriolar hyalinosis) in the subcutaneous tissue and the slope of the autoregulation curves of the subcutaneous blood flow in $\bullet=$ healthy controls, $\square=$ Type 1 diabetic patients without clinical nephropathy and retinopathy, $=$ Type 1 diabetic patients with clinical nephropathy and retinopathy. The figures in parentheses are the patient number. Spearman rank correlation coefficient $r=0.35$, $p<0.05$

$150 \mathrm{mmHg}$ (subjects 2, 5, 7). This break-through of the autoregulation response at approximately $150 \mathrm{mmHg}$ was not seen in the six normal subjects reaching the same high pressure level. There were no apparent differences between the three diabetic patients with an abnormal response and the remainder of the short-term diabetic patients.

In six of the eight Type 1 diabetic patients with clinical nephropathy and retinopathy, subcutaneous blood flow decreased and increased almost linearly with changes in arterial blood pressure (Fig. 1). The blood flow changed approximately $20 \%$ per $10 \mathrm{mmHg}$ change in arterial blood pressure. The slope of the autoregulation curves was significantly higher than that of the healthy and diabetic subjects without clinical microangiopathy ( $p<0.02$ for both) (Fig. 2).

Two diabetic patients with impaired autoregulation were reexamined. Again they had severely impaired autoregulation and there was no difference between measurements with or without lidocaine in the investigated area (Fig.3). The coefficient of variation (SD $\times$ $100 /$ mean) was $18 \%(n=3)$ and $26 \%(n=2)$, respectively.

\section{Histology}

Semi-quantitative light microscopy examination showed increased PAS-positive material in the terminal arteriolar basement membranes of diabetic patients with clinical microangiopathy compared with both control groups ( $p<0.02$, Fig. 2). However, no patient had severely increased basement membranes. A relationship 


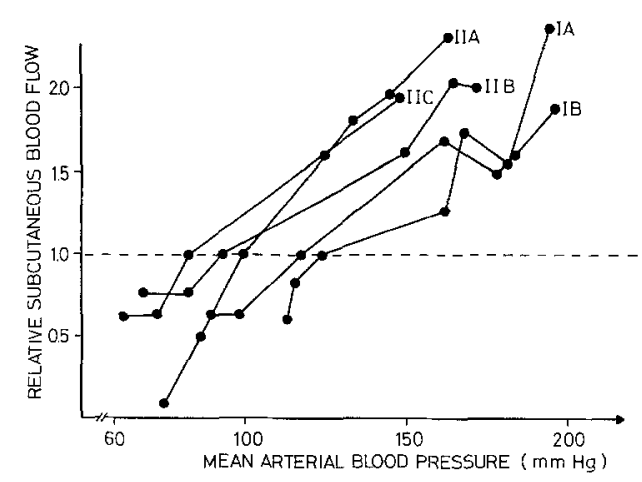

Fig. 3. Re-investigation of the autoregulation curve in two Type 1 diabetic patients with clinical microangiopathy. I $B$ and II C were made without lidocaine in the investigated area. I is patient 4 and II is patient 1 (Tables 1 and 2). Relative subcutaneous blood flow is the blood flow during changed blood pressure divided with the mean value of the blood flow in horizontal position before and after the change in blood pressure. Mean arterial blood pressure is the calculated blood pressure in the investigated area


Fig. 4. Subcutaneous blood flow and vascular resistance during headup tilt $\left(60^{\circ}\right)$. The relative subcutaneous blood flow is the blood flow during head-up tilt divided with the mean value of the blood flow in horizontal position before and after head-up tilt. The relative subcutaneous vascular resistance is the calculated vascular resistance during head-up tilt divided with the mean value of the vascular resistance in the horizontal position before and after head-up tilt

was demonstrated between the slope of the autoregulation curve and the amount of PAS positive material in the arteriolar walls (Fig. 2). Spearman rank correlation coefficient $r=0.35, p<0.05$.

\section{Neuropathy}

Five of the eight diabetic patients with clinical microangiopathy had signs of diabetic neuropathy of the peripheral somatosensory system (Table 2). However, all eight subjects had intact autonomous (sympathetic) nerve activity in the tissue area since they had a normal reduction in blood flow upon head-up tilt [24] (Fig. 4). No correlation was seen between peripheral neuropathy and disturbed autoregulation of blood flow. The short-term diabetic and control subjects were all without detectable peripheral neuropathy.

\section{Blood pressure}

There was the same age and sex distribution in the three studied groups, but the resting MAP was significantly higher in group 1 (median: $107 \mathrm{mmHg}$, range: $92-$ $128 \mathrm{mmHg}$ ) (Table 2) compared with group 3 (91 $\mathrm{mmHg}$, range: $83-104 \mathrm{mmHg}$ ) and group 2 ( $85 \mathrm{mmHg}$, range: $80-93 \mathrm{mmHg})(p<0.02$ and $p<0.01$ respectively) (Table 2). The ankle and toe systolic blood pressures were almost equal to or greater than the arm systolic pressure in all groups, indicating no significant large vessel narrowing (Table 2 ).

There was no difference in fasting blood glucose during the investigation between the diabetic patients with (median: $7.2 \mathrm{mmol} / \mathrm{l}$, range: $4.1-13.4 \mathrm{mmol} / \mathrm{l}$ ) and without $(9.3 \mathrm{mmol} / \mathrm{l}, 4.1-15.2 \mathrm{mmol} / \mathrm{l})$ clinical microangiopathy.

\section{Discussion}

The validity of our finding depends on the methods used. The local isotope washout technique allows measurement of relative blood flow in a single tissue $[18,29]$. Several studies have shown that venous pressure elevation induces a reduction in blood flow by means of a local sympathetic veno-arteriolar axon reflex mechanism [30-32]. We obtained local nerve paralysis by local injection of lidocaine in order to avoid the influence of sympathetic nerve activity. It has been demonstrated in several studies that denervated tissues and organs have completely normal autoregulation of blood flow [2]. All the control subjects had normal autoregulation of blood flow, implying that the concentration of lidocaine used was without any significant influence on the autoregulatory response. Moreover we found impaired autoregulation in two of the long-term diabetic patients studied both with and without lidocaine. These considerations suggest that the method used for investigation of the autoregulation of subcutaneous blood flow in the limb of man is valid.

We have demonstrated that autoregulation of the subcutaneous blood flow is impaired during both reduction and elevation of arterial blood pressure in most of our subjects with clinical microangiopathy. This confirms and extends the findings of Faris et al. [13]. Blood flow increased or decreased almost linearly with changes in arterial blood pressure, indicating a practically pressure-passive microvascular bed. It should be mentioned that a wide variation in autoregulatory re- 
sponses from normal to severely impaired autoregulation was demonstrated. In addition, three out of six short-term diabetic patients had decreased autoregulatory response when the arterial blood pressure approached the upper blood pressure limit for normal autoregulation.

The basis for impaired autoregulation of blood flow in subcutaneous tissue might involve either structural changes and/or metabolic disturbance of the smooth muscle cells in the arterioles. Our study revealed a relationship between the degree of hyalinosis in the terminal arterioles and impaired autoregulation. However, this does not exclude the possibility that local metabolic disturbances due to diabetes affecting the arteriolar smooth muscle activity might be of importance. During the investigation the fasting blood glucose concentration was nearly identical in the short- and long-term diabetic groups. However, we had not performed $\mathrm{HbA}_{1 \mathrm{c}}$ measurements or home monitoring of blood glucose before the investigation. It is therefore not possible to exclude the possibility that local metabolic disturbances of carbohydrate metabolism are important in the abnormal blood flow autoregulatory response in long-term diabetic patients.

Could atherosclerosis or hypertension play a role in the development of impaired autoregulation? This is not likely as the patients with clinical microangiopathy had no clinical evidence of large vessel disease affecting the lower limbs. Arterial blood pressure was elevated, but frank hypertension was only present in one of the eight long-term diabetic patients. Moreover there was no relationship between the basal blood pressure readings and impairment of autoregulation. This is in accordance with the findings of Strandgaard [33]. He found preserved autoregulation of cerebral blood flow in patients with severe arterial hypertension.

Neuropathy also seems to be of little or no importance in the abnormal autoregulatory response. There was no correlation between somatosensory neuropathy and impaired autoregulation. During head-up tilt $\left(60^{\circ}\right)$ the sympathetic nervous system was activated, resulting in peripheral vasoconstriction and an approximately halving in blood flow. This reflex vasoconstriction was not disturbed in any of the subjects investigated. This may suggest that terminal arterioles are responsible for the autoregulatory response, while the large arterioles or small arteries are the effector organ for sympatheticmediated vasoconstriction. Another possibility is that the pathological process primarily affects the delicate intrinsic mechanism(s) underlying the autoregulatory response.

It seems that metabolic disturbances, atherosclerosis, hypertension and neuropathy are of little or no importance in the discovered disturbance of the autoregulatory response. The most likely explanation is that hyalinosis of terminal arterioles impairs the normal vascular adjustment upon changes in arterial blood pressure. It is difficult to verify this hypothesis histologically be- cause of the sporadic distribution of subcutaneous microangiopathy [34]. The used semiquantitative grading of the microangiopathy is a subjective and rather crude index of arteriolar hyalinosis. A planiometric measurement of the arteriolar hyalinosis using electron microscopy would be preferable, but it is not applicable because of ignorance of the angle at which the blood vessel is cut. However, we found a significant relationship between hyalinosis of the terminal arterioles and impaired autoregulation of blood flow.

The clinical significance of impaired autoregulation of subcutaneous blood flow is lack of, or diminished, protection against hypo- or hyperperfusion induced by alterations in arterial blood pressure. A reduction of local arterial blood pressure due to proximal occlusive arterial disease may cause a larger fall in skin perfusion in diabetic patients with microangiopathy than in atherosclerotic patients without diabetic microangiopathy [35]. Consequently these patients may be more suseptible to developing tissue ischaemia (foot ulcers) at a higher arterial blood pressure than non-diabetic patients.

Acknowledgements. J. Kastrup received a research scholarship from the University of Copenhagen. We wish to thank L. Sørensen for her excellent secretarial assistance. The study was supported by a grant from Novo Foundation.

\section{References}

1. Johnson PC (1964) Review of previous studies and current theories of autoregulation. Circ Res 14 (Suppl 1): 2-9

2. Folkow B (1949) Intravascular pressure as a factor regulating the tone of small vessels. Acta Physiol Scand 17:289-310

3. Henriksen O, Nielsen SL, Paaske WP (1973) Autoregulation of blood flow in human adipose tissue. Acta Physiol Scand 89: $531-537$

4. Henriksen O, Nielsen SL, Paaske WP, Sejrsen P (1973) Autoregulation of blood flow in human cutaneous tissue. Acta Physiol Scand 89: $538-543$

5. Johnson PC (1960) Autoregulation of intestinal blood flow. Am J Physiol 199: 311-318

6. Lassen NA (1964) Autoregulation of cerebral blood flow. Circ Res 14-15 (Suppl 1): 301-304

7. Shipley RE, Study RS (1951) Changes in renal blood flow, extraction of inulin, glomerular filtration rate, tissue pressure and urine flow with acute alteration of renal artery blood pressure. Am J Physiol 167: 676-688

8. Baylis G (1902) On the local reactions of the arterial wall to changes in internal pressure. J Physiol (Lond) 28: 220-231

9. Folkow B (1964) Description of the myogenic hypothesis. Circ Res 14 (Suppl 1): 279-285

10. Johnson PC (1977) The myogenic response and the microcirculation. Microvase Res 13: 1-18

11. Anrep G (1912) On local vascular reactions and their interpretation. J Physiol (Lond) 45: 318-327

12. Berne RM (1964) Metabolic regulation of blood flow. Circ Res 15 (Suppl 1): 261-267

13. Faris I, Nielsen HV, Henriksen O, Parving H-H, Lassen NA (1983) Impaired autoregulation of blood flow in skeletal muscle and subcutaneous tissue in long-term Type 1 (insulin-dependent) diabetic patients with microangiopathy. Diabetologia 25:486-488

14. Parving H-H, Kastrup J, Smidt UM, Andersen AR, Feldt-Rasmussen B, Sandahl Christiansen J (1984) Impaired autoregulation 
of glomerular filtration rate in Type 1 (insulin-dependent) diabetics with diabetic nephropathy. Diabetologia 27: 547-552

15. Bentsen N, Larsen B, Lassen NA (1975) Chronically impaired autoregulation of cerebral blood flow in long-term diabetics. Stroke 6: 497-502

16. Sinclair SH, Grunwald JE, Riva CE, Braunstein SN, Nichols CW, Schwartz SS (1982) Retinal vascular autoregulation in diabetes mellitus. Ophthalmology 89: 748-750

17. Larsen OA, Lassen NA, Quaade F (1966) Blood flow through human adipose tissue determined with radioactive Xenon. Acta Physiol Scand 66: 337-345

18. Nielsen SL (1972) Adipose tissue blood flow determined by the washout of locally injected ${ }^{133}$ Xenon. Scand J Clin Lab Invest 29: $31-36$

19. Kety SS (1951) The theory and applications of the exchange of inert gas at the lungs and tissues. Pharmacol Rev 3:1-41

20. Henriksen O, Sejrsen $\mathbf{P}$ (1977) Local reflex in microcirculation in human skeletal muscle. Acta Physiol Scand 99:19-26

21. Nielsen HV (1982) Effect of vein pump activation upon muscle blood flow and venous pressure in the human leg. Acta Physiol Scand 114: $481-485$

22. Jersild M, Lauritzen E (1957) Sensibilité vibratroire chez les diabetiques. Diabéte 6: 237-241

23. Henriksen $O$ (1976) Local nervous mechanism in regulation of blood flow in human subcutaneous tissue. Acta Physiol Scand 97: 385-391

24. Skagen K (1982) Contribution of local blood flow regulation mechanisms during head-up tilt in human subcutaneous tissue. Acta Physiol Scand 116: 331-334

25. Bader H, Meyer DS (1977) The size of the juxtaglomerular apparatus in diabetic glomerulosclerosis and its correlation with arteriosclerosis and arterial hypertension: a morphometric light microscopic study on human renal biopsies. Clin Nephrol 8: 308-311

26. Nielsen PE, Bell G, Lassen NA (1973) Strain gauge studies of distal blood pressure in normal subjects and in patients with peripheral arterial disease. Analysis of normal variation and reproduci- bility and comparison to intra-arterial measurements. Scand $\mathrm{J}$ Clin Lab Invest 31 (Suppl) 128: 103-109

27. Mancini G, Carbonara AO, Heremans JF (1965) Immunochemical quantitation of antigens by single radial immunodiffusion. Immunochemistry 2:235-254

28. Bröchner-Mortensen J, Giese J, Rossing N (1969) Renal inulin clearance versus total plasma clearance of ${ }^{51} \mathrm{Cr}$-EDTA. Scand J Clin Lab Invest 23: 301-305

29. Sejrsen P (1971) Measurement of cutaneous blood flow by freely diffusible radioactive isotopes. MD Thesis. Copenhagen. Dan Med Bull Suppl 18

30. Henriksen $O(1977)$ Local sympathetic reflex mechanism in regulation of blood flow in human subcutaneous adipose tissue. MD Thesis Acta Physiol Scand Suppl 450

31. Henriksen O, Sejrsen P (1976) Local reflex in microcirculation in human cutaneous tissue. Acta Physiol Scand 98: 227-231

32. Henriksen O, Sejrsen P (1977) Local reflex in microcirculation in human skeletal muscle. Acta Physiol Scand 99: 19-26

33. Strandgaard S (1976) Autoregulation of cerebral blood flow in hypertensive patients. Circulation 53:720-727

34. Vracko R (1970) Skeletal muscle capillaries in diabetics. Circulation 41: 271-283

35. Kastrup J, Lassen NA, Parving H-H (1984) Diabetic microangiopathy, a factor enhancing the functional significance of peripheral occlusive arteriosclerotic disease. Clin Physiol 4: 367-369 (Editorial)

Received: 3 January 1985

and in revised form: 5 August 1985

Dr. J. Kastrup

Department of Clinical Physiology/Nuclear Medicine

Bispebjerg Hospital

Bispebjerg Bakke 23

DK-2400 Copenhagen NV

Denmark 